\title{
GRAU DE MATURIDADE NA GESTÃO DAS EMPRESAS DE CONFECÇÃO EM SANTA CRUZ DO CAPIBARIBE (PE)

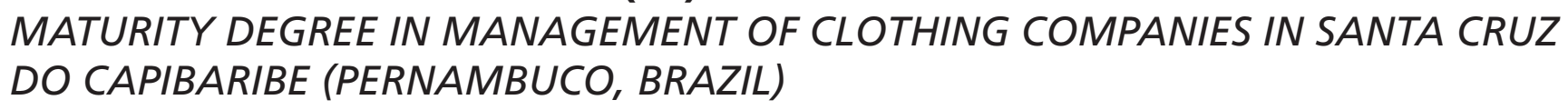

\section{Stêvenis Moacir Moura da Fonseca}

Mestre em Administração pela Universidade de Pernambuco (UPE), Recife (PE), Brasil

\section{Andréa Pereira da Silva}

Mestre em Administração/Gestão do Desenvolvimento Local Sustentável pela UPE, Recife (PE), Brasil
Data de recebimento: 04-09-2015

Data de aceite: 13-10-2016

\section{RESUMO}

Este estudo visa avaliar o grau de maturidade de empresas do setor têxtil e de confecções no Agreste pernambucano, especificamente no município de Santa Cruz do Capibaribe. Dessa maneira, foi aplicado o diagnóstico da matriz de competitividade, proposta pela Fundação Nacional da Qualidade, seguindo as diretrizes do Modelo de Excelência da Gestão. Assim, foi possível realizar diagnóstico gerencial da qualidade e da sustentabilidade dos empreendimentos. Utilizou-se a metodologia de estudo de caso, cuja abordagem foi qualiquantitativa, com a aplicação de questionário a 25 empresas. Foi por meio desse instrumento que se identificaram o grau de maturidade e os itens que precisavam ser melhorados pelas empresas para que elas continuassem no mercado, mantendo e/ou ampliando sua parcela de mercado. Os resultados obtidos sugerem que, pela média do grau de maturidade, os empreendimentos analisados encontram-se imaturos. Nesse caso, eles necessitam avançar na gestão e melhorar significativamente seus indicadores.

Palavras-chave: Grau de maturidade; aglomerações produtivas; matriz de competitividade.

\section{ABSTRACT}

This study aims to assess the level of business' maturity of textiles and clothing companies in the agreste of Pernambuco (Brazil), specifically in Santa Cruz do Capibaribe. Thus, competitiveness matrix diagnosis - proposed by the Fundação Nacional da Qualidade, following the guidelines of the Management Excellence Model - was applied. In this way, it was possible to perform a managerial diagnosis of the enterprises' quality and sustainability. Case study methodology was used, with qualitative and quantitative approach, through the application of a questionnaire to 25 companies. It was through this instrument that the maturity degree and which items needed to be improved by the companies to stay in business while maintaining and/or increasing its market share were identified. The results suggest that, according to the average maturity degree, the analyzed enterprises are immature. In this case, they need to advance in the management and significantly improve its indicators.

Keywords: Maturity degree; productive agglomerations; competitiveness matrix. 


\section{INTRODUÇÃO}

O estado de Pernambuco foi um dos grandes produtores do setor têxtil do Brasil, até a metade do século XX (DIEESE, 2010). Hoje, a concentração de empresas de confecção e têxtil no estado encontra-se principalmente na região Agreste, denominada Polo de Confecções do Agreste Pernambucano, que abrange 16 municípios. Entre eles, destacam-se Santa Cruz do Capibaribe, Caruaru e Toritama, onde tudo começou (DIEESE, 2010; LIRA, 2006; SEBRAE/PE, 2013).

Na década de 1990, o polo foi submetido a reestruturação produtiva, após a qual passou a ser designado como Arranjo Produtivo Local (APL). Sua trajetória é caracterizada pela ação empreendedora local e autônoma, que intenta modificar cenário de poucas expectativas de sobrevivência e predominância de micro e pequenos empreendimentos e de relações de trabalho informais e precarizadas; além disso, esse APL é fator relevante para o desenvolvimento econômico da região.

Com os mercados mais complexos e imprevisíveis, demandam-se novos fatores estruturais que garantam a competitividade das empresas, que passaram a ser influenciadas pela velocidade e pela capacidade de integração, inovação e conhecimento (CASTELLS, 1999; KOTLER; ARMSTRONG, 2000; PORTER, 1999). Tais fatores exigem atenção especial, principalmente por questões de sobrevivência e desenvolvimento das micro e pequenas empresas.

Em síntese, existem importantes dificuldades de adequação da realidade local às demandas de mercado. Entretanto, o espírito empreendedor desses atores que conceberam o Polo de Confecções do Agreste Pernambucano possibilita vislumbrar expectativas otimistas em relação a essas adequações, em virtude do seu potencial inovador, além das demais inter-relações que se constituíram nesse APL. Por essa razão, relevam-se estudos sobre o grau de maturidade de gestão, com alcunha de estimular e implementar práticas sustentáveis de gestão.

Os arranjos produtivos locais correspondem a uma das formas organizacionais nas quais as relações possibilitam troca de informações entre seus agentes, bem como suporte e conhecimento de instituições públicas e privadas, com intuito de viabilizar o desenvolvimento endógeno.

Diante da dinamicidade desse contexto, o município de Santa Cruz do Capibaribe foi escolhido entre os demais que constituem o Polo de Confecções do Agreste Pernambucano, sobretudo em virtude da relevância da indústria de confecção desse município. Sendo assim, o objetivo desta pesquisa foi avaliar o grau de maturidade de empresas do setor têxtil e de confecções santa-cruzense, realizando diagnóstico gerencial, da qualidade e da sustentabilidade dos empreendimentos, de forma a evidenciar os aspectos positivos e os que estão dificultando o desenvolvimento do negócio.

Este estudo está dividido em cinco seções, incluindo a introdução. A segunda seção traz revisão de literatura. Em seguida, são descritos os procedimentos metodológicos, baseados em análise qualiquantitativa e em dados obtidos em pesquisa exploratório-descritiva e de campo; os sujeitos da pesquisa foram empreendedores do município de Santa Cruz do Capibaribe. Na quarta seção, são apresentados os resultados e, por último, são tecidas as considerações finais deste estudo.

\section{REVISÃO DE LITERATURA}

\subsection{Breve histórico do polo}

O Polo de Confecções do Agreste Pernambucano se originou na década de 1960, concomitantemente nos municípios de Santa Cruz do Capibaribe, Caruaru e Toritama, a partir da iniciativa de pequenos empreendedores locais. Ele surgiu sem a intervenção do Estado, em virtude da decadência 
da produção de algodão, das indústrias têxteis da Região Metropolitana do Recife, dos curtumes e da fabricação artesanal de sapatos de couro sintético, especificamente de policloreto de vinil (PVC) (DIEESE, 2010; SEBRAE/PE, 2013).

Em síntese, os empreendedores são responsáveis por introduzir inovações e promover mudanças na cadeia produtiva. De acordo com Schumpeter (1997), o espírito empreendedor pode assumir muitas e variadas formas, entre elas o cooperativismo, e assim transformar a realidade de uma localidade. No Brasil, as políticas públicas implementadas na região Nordeste visando à industrialização eram, geralmente, ineficazes e atrasadas, conforme argumenta Moreira (1979) quando compara as políticas de desenvolvimento do Nordeste e do Centro-Sul. Enquanto "se desenvolvia no Centro-Sul uma política de inversões dentro de um programa orientado com objetivos definidos, no Nordeste se levava a cabo uma política 'assistencialista'" (MOREIRA, 1979, p. 43). A ação governamental no Nordeste centrava-se na "política de combate às secas" (MOREIRA, p. 46) e tinha efetivamente um "caráter filantrópico" (MOREIRA, 1979, p. 46).

Assim sendo, inicia-se em Santa Cruz do Capibaribe, por meio da mobilização social, uma produção artesanal de roupas, colchas e tapetes a partir de retalhos de malhas, adquiridos nas fábricas do Recife e principalmente nas de São Paulo, através de caminhoneiros, sem custo algum para as agricultoras do município. Essa produção era vendida nas calçadas do centro da cidade; em seguida, nas feiras livres semanais destinadas exclusivamente à venda da sulanca, denominadas de Feiras da Sulanca. O termo "sulanca" refere-se à aglutinação das palavras "sul" e "helanca", ou seja, "helanca vinda do sul", e simboliza produtos simples e de baixo custo destinados ao mercado popular (DIEESE, 2010; LIRA, 2006; SEBRAE/PE, 2013).
Em seguida, a sulanca passa a ser também comercializada pelos próprios produtores santa-cruzenses na secular feira de Caruaru. Com o tempo, Caruaru, que é considerado o principal município da região e que tradicionalmente já detinha setor de confecção diversificado, torna-se também produtor de sulanca, assim como Toritama, que se especializou em produção e confecção de jeans entre as décadas de 1970 e 1980. Na década de 1980, cada um dos três municípios passou a ter suas próprias feiras de sulanca organizadas pelos governos municipais, o que estabeleceu competição entre eles (LIRA, 2006). Todavia, foram a sinergia e a valorização de suas especificidades que alavancaram essa cadeia produtiva, conforme pontuam Duarte e Fusco (2008):

a expansão da indústria de confecção naquela porção do Agreste de Pernambuco deve-se a uma conjunção de fatores, dentre os quais vale destacar a proximidade da cidade de Caruaru, que, além de ser um importante polo econômico sub-regional, abriga a maior feira ao ar livre do interior nordestino. Sem Caruaru, dificilmente a indústria da sulanca teria prosperado em Santa Cruz do Capibaribe; sem esta, provavelmente Toritama teria continuado a exibir o pouco dinamismo que ainda hoje se observa na maioria das cidades do Agreste pernambucano. (DUARTE; FUSCO, 2008, p. 338).

Para a aproximação do Estado com os aglomerados de micro e pequenas indústrias do Agreste, contribuíram tanto o debate internacional sobre a reestruturação da cadeia produtiva quanto aspectos como a especialização setorial, os aglomerados produtivos, a proximidade geográfica e a valorização das pequenas e médias empresas (AMIN, 1999; LASTRES; CASSIOLATO, 2003a; LASTRES; CASSIOLATO, 2003b; SCHMITZ, 1997).

Desse modo, é na década de 1990 que a atividade têxtil e de confecções foi se expandindo para outros municípios da região. Os produtos foram 
ganhando qualidade enquanto o poder público contribuía com políticas públicas de crédito para os microempreendedores e com ações de qualificação por meio do Sistema S (DIEESE, 2010). Com isso, fortaleceram-se as chances de sobrevivência e crescimento dessa atividade, o que fez que o enfoque tradicional baseado em estratégia individual se apresentasse inadequado e forçou a adoção de estratégia coletiva.

Nos anos 2000, emerge a necessidade de inovar, diante da competição com outros estados brasileiros e com os produtos chineses, além de conquistar novos mercados, explorando os conceitos de moda e constituindo uma moda pernambucana (DIEESE, 2010; LIRA, 2006; SEBRAE/PE, 2013). Para isso, foram realizados investimentos educacionais - por exemplo, em cursos técnicos e na construção de universidades públicas que incluem cursos dedicados ao segmento de moda - no município de Caruaru. Buscou-se também a modernização do processo de comercialização através da concepção do Moda Center, em Santa Cruz do Capibaribe, do Parque de Feiras, em Toritama, e do Polo Comercial, em Caruaru, que são considerados shoppings populares. Entretanto, os principais desafios são a alta taxa de informalidade dos empreendimentos, a melhoria na infraestrutura e a questão ambiental (DIEESE, 2010).

É pertinente destacar, de acordo com Schumpeter (1997), que a inovação é a força central do dinamismo do sistema capitalista. Logo, reporta-se a processo coletivo e social que contempla vários tipos de inovação, tais como organizacional, produtiva, de marketing e de processos.

Hoje, além de Santa Cruz do Capibaribe, Caruaru e Toritama, mais treze municípios da região integram o polo, que são: Agrestina, Bezerros, Brejo da Madre de Deus, Cupira, Frei Miguelino, Riacho das Almas, Santa Maria do Cambucá, São Caetano, São Joaquim do Monte, São Vicente Ferrer, Surubim, Tacaimbó e Taquaritinga do Norte (DIEESE, 2010). Entretanto, os três municípios pioneiros juntos são responsáveis por $70 \%$ da produção do polo (SEBRAE/PE, 2013).

\subsection{Desenvolvimento local e regional - sistemas e arranjos produtivos}

A literatura apresenta a transformação do tradicional modelo de produção fordista (centralizado em grandes empresas) para a produção flexível, que caracteriza-se por ser descentralizada e sistêmica a partir de sua rede de relações e estratégias, com foco na inovação e com a participação integralizada de grandes, médias e pequenas empresas no processo produtivo. Consequentemente, tal transformação promoveu profundas mudanças nos sistemas produtivos locais e no desenvolvimento regional (AMIN, 1999; CASTELLS, 1999; LASTRES; CASSIOLATO, 2003a; LASTRES; CASSIOLATO, 2003b; PORTER, 1999).

Em resposta às crises econômicas das décadas de 1970 e 1980 e às diretrizes do Relatório de Brundtland, que propõe a conciliação do desenvolvimento econômico com a preservação ambiental e a justiça social em 1987, o processo de globalização e a celeridade da informação contribuíram para reorientação do desenvolvimento econômico local e regional - além de global, consequentemente. Nesse contexto destacam-se as aglomerações produtivas como estruturas capazes de competir e sobreviver no mercado atual.

Por essa razão é bom lembrar do que defendia Schumpeter (1997): que real desenvolvimento ocorrerá apenas com mudanças que não Ihe sejam impostas, mas que emerjam de dentro da sociedade com iniciativa própria, constituindo processo contínuo de mudanças e proporcionando ganhos qualitativos para a localidade.

A análise de Amin (1999) sobre políticas de desenvolvimento local e regional enfatiza a confluência entre a vertente keynesiana e a neoliberal. De um lado, o legado keynesiano desde os anos 1960 atua com políticas de redistribuição de renda 
e bem-estar para estimular as regiões menos favorecidas, e incentivos fiscais para empresas nessas regiões; de outro lado, o neoliberalismo centra-se nas falsas virtudes do mercado e na capacidade empresarial para conduzir desenvolvimento regional, além de iniciativas para estimular o espírito empreendedor. Entretanto, na prática, ambas as vertentes obtiveram resultados modestos nas regiões mais desfavorecidas, entre as quais estão países em desenvolvimento.

Ainda segundo Amin (1999), em objeção ao dualismo entre ambas as vertentes começaram a ser desenvolvidas alternativas que buscavam promover a competitividade por meio da mobilização do potencial endógeno das regiões, principalmente em virtude da experiência exitosa italiana nos anos 1970 - especificamente a Terceira Itália, de onde emergiram os distritos industriais italianos ou clusters.

As principais características dos clusters italianos são a concentração de médias e pequenas empresas num território; a especialização setorial; a valorização das potencialidades endógenas; a colaboração entre as empresas; a competição entre as empresas baseada na inovação; a identidade sociocultural que favorece confiança; o apoio governamental (AMIN, 1999; SCHMITZ, 1997).

Dessa maneira, o processo de clustering vem configurando-se como nova alternativa de desenvolvimento regional, inclusive no Brasil, desde os anos 1990. Esse processo foi inicialmente descrito por Marshall (1996), no século XIX, para caracterizar as concentrações de pequenas e médias empresas localizadas ao redor de grandes indústrias na Inglaterra, denominadas distritos industriais. Tais aglomerações geográficas e especializadas dão origem aos contemporâneos conceitos de clusters.

Para Schmitz (1997, p. 172), apesar de Marshall não ter mencionado claramente distrito industrial e cluster, "seus exemplos deixam claro que quis dizer um cluster, como uma divisão do trabaIho profunda de firmas". Desse modo, a expressão "distrito industrial" também se refere a cluster; ou seja, a "vantagem de usar o termo cluster é que ele se refere a apenas uma concentração setorial e geográfica de firmas" (SCHMITZ, 1997, p. 173). Por essa razão, Schmitz (1997, p. 173) afirma: "no que se segue, os termos 'distrito industrial' e 'cluster' são, algumas vezes, intersubstituíveis, mas vale a pena recordar que, embora um distrito industrial seja sempre um cluster, o inverso nem sempre é verdadeiro".

Conforme o enunciado de Schmitz (1997), hoje o conceito de distrito industrial refere-se a divisão de trabalho e também implica em cooperação, enquanto o conceito de cluster refere-se a concentração setorial e geográfica de empresas, com divisão do trabalho, não sendo obrigatório o fator cooperação.

Porter (1999, p. 211) redefiniu o conceito de cluster como "um agrupamento geograficamente de empresas concentradas inter-relacionadas e instituições correlatas numa determinada área, vinculada por elementos comuns e complementares".

Marshall (1996, p. 315) observou que as duas principais fontes de eficiência das empresas localizadas nesses distritos industriais deviam-se às economias internas e externas. As primeiras "dependem dos recursos das empresas que a elas se dedicam individualmente, das suas organizações e eficiência de suas administrações", ao passo que as segundas "dependem do desenvolvimento geral da indústria".

Sucintamente, as economias internas caracterizam-se pelo grau de maturidade de gestão da empresa, enquanto as economias externas correspondem aos ganhos adquiridos pela empresa no mercado, independentemente de sua ação, considerando as vantagens oriundas das inter-relações empresariais e a existência de fatores como infraestrutura, mão de obra qualificada, matéria-prima e informações.

Sob esse aspecto, destaca-se a importância das economias externas, principalmente para as 
pequenas empresas. Sendo assim, a constituição de clusters tende a fortalecer os pequenos empreendimentos e contribuir para o desenvolvimento endógeno. Dessa maneira, na literatura há consenso de que os clusters industriais auxiliam as pequenas e médias empresas a superar os obstáculos de crescimento e a competir por mercados (AMIN, 1999; LASTRES; CASSIOLATO, 2003a; LASTRES; CASSIOLATO, 2003b; SCHMITZ, 1997).

Ao analisar a realidade dos clusters industriais em países em desenvolvimento, Schmitz (1997, p. 179) argumenta que

a formação de clusters não tem sido o resultado de uma intervenção planejada do Estado, tendo emergido de dentro para fora. Isso empresta crédito à visão segundo a qual, como nos casos dos distritos europeus, a eficiência coletiva baseada nas atividades econômicas e sociais de uma comunidade é difícil de ser criada de cima para baixo e se desenvolvem meIhor como um processo endógeno. Todavia o Estado, particularmente em nível regional, pode desempenhar um papel facilitador importante para os clusters de pequenas firmas.

Os clusters, então, "tendem a estar associados com alguma identidade sociocultural comum" (SCHMITZ, 1997, p. 178).

De maneira geral, o reconhecimento da relevância de clusters para promover a fomentação ou implementação do desenvolvimento local e regional proporcionou a evolução conceitual das aglomerações produtivas ou simplesmente de cluster industrial (PORTER, 1999), arranjos produtivos locais e sistemas (LASTRES; CASSIOLATO, 2003a; SCHMITZ, 1997) e redes (CASTELLS, 1999).

No Brasil, tem sido comum o uso do termo APL para se referir às aglomerações produtivas em virtude das pesquisas da Rede de Sistemas Inovativos Locais da Universidade Federal do Rio de Janeiro (RedeSist/UFRJ). Desse modo, Lastres e Cassiolato (2003b) definem APL da seguinte maneira: os arranjos produtivos locais são aglomerações territoriais de agentes econômicos, políticos e sociais - com foco em um conjunto específico de atividades econômicas - que apresentam vínculos mesmo que incipientes. Geralmente envolvem a participação e a interação de empresas - que podem ser desde produtoras de bens e serviços finais até fornecedores de insumos e equipamentos, prestadoras de consultoria e serviços, comercializadoras, clientes, entre outros - e suas variadas formas de representação e associação. Incluem também diversas outras instituições públicas e privadas voltadas para: formação e capacitação de recursos humanos, como escolas técnicas e universidades; pesquisa, desenvolvimento e engenharia; política, promoção e financiamento. Os sistemas produtivos e inovativos locais são aqueles arranjos produtivos em que interdependência, articulação e vínculo consistentes resultam em interação, cooperação e aprendizagem, com potencial de gerar o incremento da capacidade inovativa endógena, da competitividade e do desenvolvimento local. (LASTRES; CASSIOLATO, 2003b, p. 3-4).

Sendo assim, no Brasil diversas iniciativas de suporte aos APL estão sendo desenvolvidas pelo poder público e por agências de fomento, destacando-se o APL Têxtil e de Confecções do Agreste (Polo de Confecções do Agreste Pernambucano). Entretanto, verifica-se a necessidade de ações contínuas e de melhor articulação com os atores envolvidos.

Amin (1999) sugere que as políticas de desenvolvimento local e regional implicam em ações práticas que promovem a atualização da base econômica local, institucional e social por meio do desenvolvimento de competências através de educação, inovação, comunicação, agências de desenvolvimento para organizações empresariais, incentivos ao empreendedorismo local e priorização de pequenas empresas e de investidores nacionais locais, com intuito de incentivar o crescimento endógeno regional a partir das especificidades locais e da valorização da cultura local, a fim de garantir 
vantagem competitiva significativa. Com isso, seria possível a construção de economia social apta a atender às necessidades de bem-estar da localidade. Entretanto, essas medidas serão inoperantes para a sustentabilidade do crescimento endógeno nas sociedades se não houver ambiente macroeconômico favorável. As sociedades por si só não serão capazes de se desenvolver sem o respaldo do ambiente institucional.

\subsection{Grau de maturidade}

O ambiente em que a maioria das empresas atua é complexo, competitivo e dinâmico, e também apresenta inúmeras oportunidades e desafios. Para transformar as oportunidades em vantagens competitivas, as empresas devem atualizar-se continuamente, buscar maturidade nos processos e eliminar a ineficiência operacional (CHRISSIS; KONRAD; SHRUM, 2011; FLEURY; FLEURY, 2000; PORTER, 1999). Sendo assim, há cada vez menos espaço para informalidade, afinal a competitividade não está apenas baseada nos fatores de produção.

O grau de maturidade corporativa está relacionado ao conhecimento endógeno constituído ao longo do tempo pela organização e à maneira como esse conhecimento se transforma em resultados efetivos, ou seja, como os processos produtivos e operacionais são planejados, executados, controlados e gerenciados.

Chrissis, Konrad e Shrum (2011, p. 41) afirmam que "o grau de maturidade é definido como um patamar evolucionário para a melhoria do processo organizacional. Cada grau de maturidade amadurece um subconjunto importante do processo da organização, preparando-a para passar para o próximo grau de maturidade".

Dessa maneira, identificar o grau de maturidade de gestão fornece informações importantes à empresa, pois evidencia os aspectos positivos e os que geram impedimentos ao desenvolvimento do negócio. Consequentemente, essa identificação pode orientar a empresa sobre os aspectos a ser desenvolvidos, compatíveis com seu estágio de maturidade gerencial.

Sendo assim, para atingir esse patamar as organizações devem desenvolver e manter a competência adequada, com eficiência e eficácia (capability). O exercício contínuo de melhoria faz que a organização atinja o mais alto patamar de maturidade (maturity) de acordo com suas potencialidades e objetivos empresariais (CHRISSIS; KONRAD; SHRUM, 2011).

Por essa razão, a relevância não é a maturidade em si, que é apenas um estado dinâmico, mas a competência em identificar e buscar o estágio necessário e suficiente, por meio da obtenção de conhecimento, do desenvolvimento das habilidades e da atitude em alinhá-los com os objetivos do negócio (FLEURY; FLEURY, 2000).

Em síntese, organizações maduras atingem seus objetivos de maneira consistente e eficiente, enquanto organizações imaturas criam seus objetivos, mas geralmente seus resultados são imprevisíveis e inconsistentes. Conforme enfatizam Chrissis, Konrad e Shrum (2011 p. 41), o sucesso nas organizações imaturas "depende da competência e heroísmo das pessoas na organização".

Na literatura há uma série de metodologias que se propõem a avaliar o grau de maturidade de gestão com a observância a aspecto ou conjunto de aspectos da gestão. Para este estudo, optou-se pelo Modelo de Excelência da Gestão (MEG), desenvolvido pela Fundação Nacional da Qualidade (FNQ), organização sem fins lucrativos criada em 1991 que tem como missão "estimular e apoiar as organizações para o desenvolvimento e a evolução de sua gestão, por meio da disseminação dos fundamentos e critérios de excelência, para que se tornem sustentáveis, cooperativas e gerem valor para a sociedade" (FNQ, 2014a, p. 17).

Essa missão explicita, em grande parte, a importância de disseminar cultura voltada para a melhoria contínua da gestão, com intuito de 
proporcionar maior competitividade às organizações brasileiras em cenário extremamente competitivo e dinâmico e de ter o modelo avaliativo MEG alinhado às especificidades locais e internacionais.

\subsection{Modelo de Excelência da Gestão (MEG)}

O MEG foi desenvolvido em 2001 e é composto por oito critérios de excelência e 37 itens, de modo a potencializar sua utilização como ferramenta de gestão para diagnóstico e planejamento das empresas brasileiras. Seu alinhamento com as principais tendências e iniciativas nacionais e internacionais em excelência de gestão proporciona a compreensão do mercado e do cenário local ou global onde a organização atua e se relaciona, além de possibilitar a avaliação do grau de maturidade da gestão nas organizações (FNQ, 2014a).

Trata-se de um modelo sistêmico, não prescritivo, que visa o aprendizado e a melhoria contínua da gestão e é anualmente atualizado pela FNQ. O Quadro 1 descreve os critérios que integram o MEG. Nesse sentido, a perspectiva sistêmica possibilita abordagem do ambiente organizacional, que é compreendido em macroambiente e microambiente - ou seja, os atores e as forças ambientais que interferem nos negócios da empresa. É necessário entender essas inter-relações que a todo momento geram novas oportunidades e ameaças para as organizações (KOTLER; ARMSTRONG, 2000; PORTER, 1999).

\section{Quadro 1 - Os critérios de avaliação do Modelo de Excelência da Gestão}

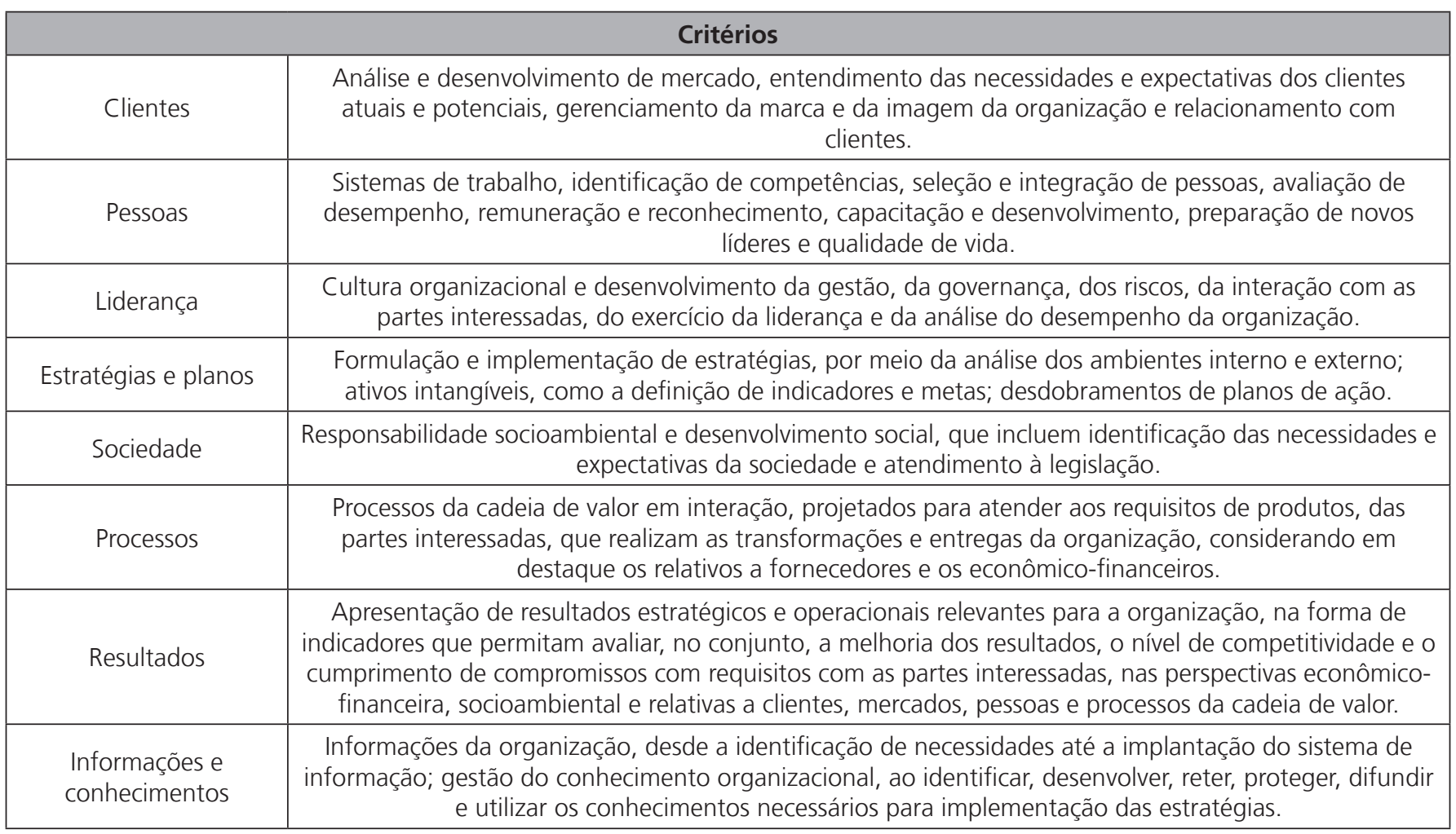

Fonte: Elaborado a partir de FNQ (2014a, p. 14-15).

Tais critérios foram baseados nos seguintes fundamentos: pensamento sistêmico, atuação em rede, aprendizado organizacional, inovação, agilidade, liderança transformadora, olhar para o futuro, conhecimento sobre clientes e mercados, responsabilidade social, valorização das pessoas e da cultura, decisões fundamentadas, orientação por processos e geração de valor (FNQ, 2014a; 2014b). Por essa razão, os critérios selecionados são aplicáveis a qualquer tipo de 
organização, independente de seu porte e setor de atuação.

A adoção desses critérios possibilita o controle de riscos e oportunidades de negócio e pode acontecer não só pela empresa, mas também pela sua cadeia de valor. Sendo assim, para disseminar o MEG, ele é utilizado na avaliação do Prêmio Nacional da Qualidade (PNQ) e do Prêmio de Competitividade para Micro e Pequenas Empresas (Prêmio MPE Brasil), cujas empresas participantes obtêm amplo diagnóstico de maturidade da gestão e ainda concorrem à premiação.

\section{PROCEDIMENTOS METODOLÓGICO}

Esta pesquisa caracteriza-se por seu caráter exploratório-descritivo, cuja abordagem foi qualiquantitativa, com a aplicação de um questionário aos empreendedores que integram o Polo de Confecções do Agreste Pernambucano - precisamente no município de Santa Cruz do Capibaribe - que se dispuseram a participar da pesquisa. Ao total foram contempladas 25 empresas de pequeno e médio porte. Os dados foram coletados em outubro de 2014.

Dessa maneira, utilizou-se como meio o estudo de caso. De acordo com Yin (2005), essa estratégia permite analisar com maior profundidade a situação em questão e, consequentemente, permite a compreensão desse fenômeno social.

Os questionários foram elaborados a partir dos oito critérios e 37 itens definidos no MEG e que compõem a Matriz de Competitividade, com seus respectivos pesos. Sendo assim, seguiu-se o roteiro estabelecido no próprio diagnóstico para avaliação das empresas. Cada diagnóstico teve duração média de 3 horas, tempo justificado pelo fato de que ainda são repassadas orientações a respeito da gestão e da busca das evidências do que o empresário relata.
Sobre a base de cálculo da pontuação para cada item e critério do MEG: atribui-se peso zero para as respostas "a"; peso 0,25 para repostas "b"; peso 0,75 para as respostas " $c$ "; e peso 1,00 para as respostas " $d$ ". Em seguida é realizado o somatório dos percentuais, por questão, e calculada média por cada critério avaliado, cuja base é 100 . Vale salientar que a pontuação zero (resposta "a") acontece quando não há qualquer evidência a respeito do ponto avaliado, e a resposta " $d$ " acontece quando aquela evidência é reconhecida e atualizada. Dessa maneira é obtido o grau de maturidade de gestão da empresa.

Para Minayo (2007, p. 61), "o trabalho de campo permite a aproximação do pesquisador da realidade sobre a qual formulou uma pergunta, mas também estabelecer uma interação com os 'atores' que conformam a realidade e, assim, constrói um conhecimento empírico importantíssimo da pesquisa social".

A principal dificuldade enfrentada para a coleta de dados dos sujeitos pesquisados foi que, se aproximando o final do ano - período de alta estação para a comercialização dos produtos -, os empresários estavam bastante voltados para a produção. Isso foi fator determinante para o número reduzido de empresários dispostos a ter esse diagnóstico de gestão, mesmo necessitando desse tipo de atendimento e demonstrando bastante interesse.

\subsection{Locus da pesquisa}

O locus da pesquisa foi o município de Santa Cruz do Capibaribe, um dos principais integrantes do Polo de Confecções do Agreste Pernambucano. O município tem 335.309 km² de área, 87.582 habitantes $^{1}$ e clima semiárido. O setor têxtil e de

\footnotetext{
1 Informações disponíveis respectivamente em <http://www.cidades.ibge.gov.br/xtras/perfil.php?lang=\&codmun=261250> e <http://www.cidades.ibge.gov.br/xtras/temas.php?lang=\&codmun $=261250 \&$ idtema $=97 \&$ search $=$ pernambuco $\% 7 C$ santa-cruz-do-capibaribe\%7Ccenso-demografico-2010:-resultados-da-amostra-migracao-->. Acesso em: 30 jan. 2017.
} 
confecções gera 3.632 postos de trabalho formais, que correspondem a 45,1\% do total de empregos no município (DIEESE, 2010). Entretanto, o índice de informalidade é bastante elevado em todo o polo e, consequentemente, em Santa Cruz do Capibaribe, conforme se verifica nas Tabelas 1 e 2, de acordo com os dados da pesquisa realizada pelo Sebrae em dez municípios que integram o polo.

Tabela 1 - Estimativas da quantidade de unidades produtivas, segundo formalidade e informalidade, em dez municípios que integram o Polo de Confecções do Agreste Pernambucano no ano de 2012

\begin{tabular}{|c|c|c|c|c|}
\hline & \multicolumn{2}{|c|}{ Unidades produtivas informais } & \multicolumn{2}{|c|}{ Unidades produtivas formais } \\
\hline Municípios & $\begin{array}{c}\text { Quantidade de } \\
\text { unidades produtivas } \\
\text { informais }\end{array}$ & $\begin{array}{c}\text { Participação das } \\
\text { informais no total das } \\
\text { unidades produtivas } \\
(\%)\end{array}$ & $\begin{array}{l}\text { Quantidade de } \\
\text { unidades produtivas } \\
\text { formais }\end{array}$ & $\begin{array}{c}\text { Participação das formais } \\
\text { no total das unidades } \\
\text { produtivas (\%) }\end{array}$ \\
\hline Agrestina & 261 & 87,3 & 38 & 12,7 \\
\hline Brejo da Madre de Deus & 1.173 & 84,0 & 223 & 16,0 \\
\hline Caruaru & 3.568 & 78,7 & 963 & 21,3 \\
\hline Cupira & 113 & 83,7 & 22 & 16,3 \\
\hline Riacho das Almas & 339 & 81,7 & 76 & 18,3 \\
\hline Santa Cruz do Capibaribe & 5.820 & 81,2 & 1349 & 18,8 \\
\hline Surubim & 304 & 63,0 & 150 & 33,0 \\
\hline Taquaritinga do Norte & 1.057 & 89,2 & 128 & 10,8 \\
\hline Toritama & 2.174 & 77,1 & 644 & 22,9 \\
\hline Vertentes & 329 & 82,0 & 72 & 18,0 \\
\hline Total & 15.138 & 80,5 & 3.666 & 19,5 \\
\hline
\end{tabular}

Nota: unidades produtivas = empresas + empreendimentos complementares.

Fonte: Sebrae/PE (2013).

Tabela 2 - Percentual de informalidade no total das unidades produtivas em Santa Cruz do Capibaribe em comparação dos resultados de 2002 e 2012

\begin{tabular}{c|c|c}
\hline \multicolumn{3}{c}{ Percentual de informalidade } \\
\hline & Ano de 2002 & Ano de 2012 \\
\hline $\begin{array}{c}\text { Santa Cruz do } \\
\text { Capibaribe }\end{array}$ & $94,3 \%$ & $81,2 \%$ \\
\hline
\end{tabular}

Fonte: Sebrae/PE (2013).

O Polo de Confecções do Agreste Pernambucano continua sendo setor dominado por micro e pequenas empresas (DIEESE, 2010; SEBRAE/PE, 2013), cuja definição ocorre segundo o Estatuto Nacional da Microempresa e Empresa de Pequeno Porte, Lei Complementar $n^{\circ} 123$, de 14 de dezembro de 2006, que utiliza o critério da receita bruta anual. O critério para encaixe na categoria de microempresas devidamente registradas nos órgãos competentes é de que aufiram anualmente a receita bruta igual ou inferior a $R \$ 360.000,00$; se a receita bruta anual for superior a $\mathrm{R} \$ 360.000,00$ e igual ou inferior a $\mathrm{R} \$ 3.600 .000,00$, a sociedade será enquadrada como empresa de pequeno porte. Essas informações estão condensadas no Quadro 2.

Quadro 2 - Definição de micro e pequena empresa

\begin{tabular}{|c|c|c|}
\hline Definição & Microempresa & Pequena Empresa \\
\hline $\begin{array}{c}\text { Estatuto Nacional da MPE }- \\
\text { Receita Bruta Anual }\end{array}$ & $=<\mathrm{R} \$ 360.000,00$ & $>\mathrm{R} \$ 360.000,00$ até $\mathrm{R} \$ 3.600 .000,00$ \\
\hline
\end{tabular}

Fonte: Elaborado a partir da Lei Complementar 123/06. 
Logo, o elevado grau de informalidade compromete o grau de maturidade das organizações, consequentemente atingindo toda a sociedade.

\section{RESULTADOS E DISCUSSÃO}

As empresas analisadas atuam em vários segmentos da área de confecção. Para a pesquisa, destacam-se as confecções de moda infantil e moda praia, com $28 \%$ e $24 \%$, respectivamente, do total de empresas. De certa forma, há equilíbrio nos segmentos das empresas avaliadas, como mostra a Tabela 3. No caso de moda surfwear, moda infantil e moda praia, não foi feita distinção entre sexo masculino e feminino.

Tabela 3 - Segmento das empresas avaliadas

\begin{tabular}{c|c}
\hline Segmento & Percentual \\
\hline Moda infantil & $28 \%$ \\
\hline Moda praia & $24 \%$ \\
\hline Moda masculina & $16 \%$ \\
\hline Moda masculina e feminina & $12 \%$ \\
\hline Surfwear & $12 \%$ \\
\hline Moda feminina & $8 \%$ \\
\hline
\end{tabular}

Fonte: Dados da pesquisa.

O grau de maturidade independe de porte da empresa - já que todas as empresas são de pequeno porte -, bem como do tipo de produto que é confeccionado. O grau de instrução do empresário não foi avaliado, entretanto aqueles que buscam mais informações de gestão possuem melhores resultados, como sugerem as Tabelas a seguir. Pode-se perceber também que o segmento não interfere no nível de gestão da empresa. Na Tabela 4 verificam-se o critério "liderança" e as suas respectivas ações.

Tabela 4 - Critério "liderança"

\begin{tabular}{|c|c|c|c|c|}
\hline & a. & b. & c. & d. \\
\hline 1. Definição da missão & $68 \%$ & $16 \%$ & $16 \%$ & $0 \%$ \\
\hline 2. Comportamento ético & $4 \%$ & $84 \%$ & $8 \%$ & $4 \%$ \\
\hline 3. Análise do desempenho & $4 \%$ & $56 \%$ & $36 \%$ & $4 \%$ \\
\hline 4. Compartilhamento de informações & $24 \%$ & $60 \%$ & $16 \%$ & $0 \%$ \\
\hline 5. Desenvolvimento gerencial & $36 \%$ & $16 \%$ & $28 \%$ & $20 \%$ \\
\hline 6. Busca de informações & $24 \%$ & $76 \%$ & $0 \%$ & $0 \%$ \\
\hline
\end{tabular}

Fonte: Dados da pesquisa.

Das empresas entrevistadas (Tabela 4), 68\% não têm a missão definida, ou a definem informalmente, caso em que ela é do conhecimento apenas dos dirigentes; $16 \%$ das empresas têm a missão definida e registrada sob a forma escrita e ela é conhecida e entendida por alguns colaboradores; nenhuma empresa tem a missão escrita e apresentada para todos os envolvidos na organização, considerando colaboradores, empresários e clientes.

Destaca-se também o item "comportamento ético", pois a maioria significativa (84\%) estimula 
esse comportamento, mas não tem isso registrado e conhecido, se limitando à informalidade.

$\mathrm{Na}$ Tabela 5 esses mesmos números se repetem na definição da visão, o que evidencia falta de planejamento estratégico, já que a missão é a razão da existência da empresa, e a visão estabelece onde ela deseja estar em futuro determinado.

Tabela 5 - Critério "estratégias e planos"

\begin{tabular}{|c|c|c|c|c|}
\hline & a. & b. & c. & d. \\
\hline 7. Definição da visão & $68 \%$ & $16 \%$ & $16 \%$ & $0 \%$ \\
\hline 8. Alcance dos objetivos & $24 \%$ & $60 \%$ & $16 \%$ & $0 \%$ \\
\hline 9. Estabelecimento de indicadores e metas & $40 \%$ & $32 \%$ & $20 \%$ & $8 \%$ \\
\hline 10. Definição dos planos de ação & $76 \%$ & $20 \%$ & $4 \%$ & $0 \%$ \\
\hline
\end{tabular}

Fonte: Dados da pesquisa.

Com o resultado da Tabela 5, destacam-se estabelecimento de indicadores e metas e definição de planos de ação. Apenas 8\% dos respondentes estabeleciam metas de curto, médio e longo prazos. Porém, como se pode perceber, nenhuma empresa criava plano de ação para alcançar e monitorar essas metas. Isso mostra que a cultura do planejamento estratégico nas empresas ainda é falha e carece de princípios básicos para se pensar em sua sustentabilidade.

Estão descritos na Tabela 6 as práticas de gestão da empresa em relação a seus clientes atuais e potenciais.

Tabela 6 - Critério "clientes"

\begin{tabular}{|c|c|c|c|c|}
\hline & a. & b. & c. & d. \\
\hline 11. Agrupamento dos clientes & $4 \%$ & $48 \%$ & $40 \%$ & $8 \%$ \\
\hline 12. Divulgação dos produtos e serviços & $4 \%$ & $80 \%$ & $12 \%$ & $4 \%$ \\
\hline 14. Avaliação da satisfação & $4 \%$ & $88 \%$ & $4 \%$ & $4 \%$ \\
\hline 15. Análise das informações obtidas & $8 \%$ & $76 \%$ & $12 \%$ & $4 \%$ \\
\hline
\end{tabular}

Fonte: Dados da pesquisa.

Quanto ao critério "clientes" (Tabela 6), os números mostram preocupação com o mercado e consequente preocupação com a segmentação dos clientes. Porém, há carência de estratégias de divulgação dos produtos e - para ocasiões em que o cliente entra em contato com a empresa - de tratamento de reclamações e avaliação da satisfação.

Na Tabela 7 revela-se a atuação da empresa em relação à sociedade no atendimento a exigências legais e aspectos socioambientais.

Tabela 7 - Critério "sociedade"

\begin{tabular}{|c|c|c|c|c|}
\hline & a. & b. & c. & d. \\
\hline 16. Exigências legais & $0 \%$ & $4 \%$ & $40 \%$ & $56 \%$ \\
\hline 17. Impacto sobre o meio ambiente & $40 \%$ & $36 \%$ & $20 \%$ & $4 \%$ \\
\hline 18. Comprometimento com a comunidade & $64 \%$ & $20 \%$ & $16 \%$ & $0 \%$ \\
\hline
\end{tabular}

Fonte: Dados da pesquisa. 
Percebe-se preocupação com as exigências legais. 96\% das empresas estão em dia com suas obrigações (dessas, 56\% estão completamente em dia e $40 \%$ estão parcialmente em dia). Entretanto, 64\% das empresas não se preocupam com a comunidade sistematicamente, ou seja, com projetos sociais. Há preocupação crescente com o impacto sobre o meio ambiente, pois os números tendem a ser equilibrados. Muito se deve às parcerias sociais, pois diversas pessoas coletam o que é descartado pelas empresas (existe demanda significativa) para reciclagem, o que acaba estimulando a economia e minimizando os impactos sobre o meio ambiente.

A Tabela 8 apresenta as informações necessárias à execução das atividades da empresa, à tomada de decisão e à maneira como o conhecimento é compartilhado na empresa.

No que diz respeito a informações e conhecimentos (Tabela 8), há percentual significativo (68\%) de estímulo ao compartilhamento do conhecimento, porém isso acontece informalmente e sem método e procedimentos claros e escritos.

Verificam-se na Tabela 9 as práticas de gestão em relação às pessoas que trabalham na empresa.

Tabela 8 - Critério "informações e conhecimentos"

\begin{tabular}{|c|c|c|c|c|}
\hline & a. & b. & c. & d. \\
\hline 19. Definição das informações & $36 \%$ & $56 \%$ & $8 \%$ & $0 \%$ \\
\hline 20. Compartilhamento do conhecimento & $24 \%$ & $68 \%$ & $4 \%$ & $4 \%$ \\
\hline 21. Melhorias nas práticas de gestão & $32 \%$ & $12 \%$ & $40 \%$ & $16 \%$ \\
\hline 22. Obtenção e utilização das informações & $8 \%$ & $60 \%$ & $28 \%$ & $4 \%$ \\
\hline
\end{tabular}

Fonte: Dados da pesquisa.

Tabela 9 - Critério "pessoas"

\begin{tabular}{|c|c|c|c|c|}
\hline & a. & b. & c. & d. \\
\hline 23. Definição das funções e responsabilidades & $24 \%$ & $72 \%$ & $4 \%$ & $0 \%$ \\
\hline 24. Critérios para seleção dos colaboradores & $40 \%$ & $28 \%$ & $20 \%$ & $12 \%$ \\
\hline 25. Capacitações dos colaboradores & $20 \%$ & $56 \%$ & $16 \%$ & $8 \%$ \\
\hline 26. Identificação e tratamento dos perigos e riscos & $4 \%$ & $8 \%$ & $88 \%$ & $0 \%$ \\
\hline 27. Promoção do bem-estar e satisfação & $40 \%$ & $28 \%$ & $20 \%$ & $12 \%$ \\
\hline
\end{tabular}

Fonte: Dados da pesquisa.

Pelos resultados encontrados na Tabela 9, 96\% das empresas não têm as funções e responsabilidades formalmente definidas - somando-se $24 \%$ que não possuem qualquer definição e $72 \%$ que possuem definição informal -, o que pode gerar alto grau de informalidade nas relações e falta de padronização nos processos. Somado a isso, o critério de seleção é pouco definido, pois apenas $12 \%$ das empresas têm claramente esse procedimento escrito.

Na Tabela 10 estão descritos os processos principais do negócio da empresa, que, executados de forma padronizada, asseguram organização do ambiente operacional. 
Tabela 10 - Critério "processos"

\begin{tabular}{|c|c|c|c|c|}
\hline & a. & b. & c. & d. \\
\hline 28. Padronização dos processos & $8 \%$ & $80 \%$ & $12 \%$ & $0 \%$ \\
\hline 29. Controle para garantir satisfação das necessidades & $0 \%$ & $92 \%$ & $4 \%$ & $4 \%$ \\
\hline 30. Seleção dos fornecedores & $0 \%$ & $72 \%$ & $28 \%$ & $0 \%$ \\
\hline 31. Controle das finanças para otimização dos recursos & $12 \%$ & $36 \%$ & $24 \%$ & $28 \%$ \\
\hline
\end{tabular}

Fonte: Dados da pesquisa.

Tabela 11 - Critério "resultados"

\begin{tabular}{c|c|c|c|c}
\hline & a. & b. & c. & d. \\
\hline 32. Satisfação do cliente & $92 \%$ & $0 \%$ & $4 \%$ & $4 \%$ \\
\hline 33. Reclamações dos clientes & $96 \%$ & $0 \%$ & $0 \%$ & $4 \%$ \\
\hline 34. Capacitações para colaboradores & $100 \%$ & $0 \%$ & $0 \%$ & $0 \%$ \\
\hline 35. Acidentes com colaboradores & $72 \%$ & $0 \%$ & $24 \%$ & $4 \%$ \\
\hline 36. Produtividade no trabalho & $72 \%$ & $8 \%$ & $16 \%$ & $4 \%$ \\
\hline 37. Margem de lucro & $52 \%$ & $20 \%$ & $8 \%$ & $20 \%$ \\
\hline
\end{tabular}

Fonte: Dados da pesquisa.

Tabela 12 - Média das empresas de confecções (matriz de competitividade)

\begin{tabular}{c|l}
\hline Liderança & $26,2 \%$ \\
\hline Estratégias e planos & $17,0 \%$ \\
\hline Clientes & $30,2 \%$ \\
\hline Sociedade & $37,7 \%$ \\
\hline Informações e conhecimento & $28,3 \%$ \\
\hline Pessoas & $30,8 \%$ \\
\hline Processos & $34,0 \%$ \\
\hline Resultados & $11,5 \%$ \\
\hline
\end{tabular}

Fonte: Dados da pesquisa.

Mesmo sendo necessários procedimentos claros e escritos a fim de gerar padronização na forma de trabalho, percebe-se que o que existe geralmente é o meio informal de passar o conhecimento técnico entre os colaboradores, o que acarreta baixo aprendizado na equipe de trabalho.

Entre as áreas em maior deficiência está o setor financeiro, pois a maior parte das empresas não possui controle eficiente e ferramentas de controle financeiro, o que impede, sobretudo, que se otimizem os recursos.
Na Tabela 11 são analisados os resultados apresentados pela empresa relativos a clientes, colaboradores, processos principais do negócio e lucratividade.

As organizações também necessitam de melhorias nos processos de produção para que sejam mais produtivas e evitem desperdícios e perdas, pois, em geral, não possuem indicadores de produtividade.

O que mais chama atenção são os seguintes itens, dentro do critério "resultados": satisfação do cliente, reclamações dos clientes e capacitações para colaboradores. Há baixa preocupação, 
generalizada, com a percepção do cliente, pois essas empresas não ouvem as reclamações nem sua satisfação (Tabela 11). Da mesma maneira, é nulo o interesse pela capacitação do funcionário através de plano de capacitação; o que acontece são treinamentos esporádicos, mas sem qualquer ligação com a atividade em que esse colaborador atua.

A Tabela 12 demonstra a média alcançada pelas empresas, considerando os critérios de avaliação da matriz de competitividade (e seus respectivos pesos).
Vale salientar que isso é apenas um estrato, já que são representadas apenas 25 empresas do setor.

Considerando-se as informações listadas nas tabelas, os percentuais dos respectivos critérios do MEG e os devidos pesos, chegou-se ao Gráfico 1.

Assim, pela média do grau de maturidade das empresas do setor de confecções da região, pode-se concluir que as empresas necessitam avançar na gestão e melhorar seus indicadores. Recomenda-se fortemente que os empresários avaliem melhor seus negócios, conheçam com mais precisão sua estrutura e possuam ferramentas de controle e evidenciação.

Gráfico 1 - Representação por modelo aranha do grau de maturidade das empresas

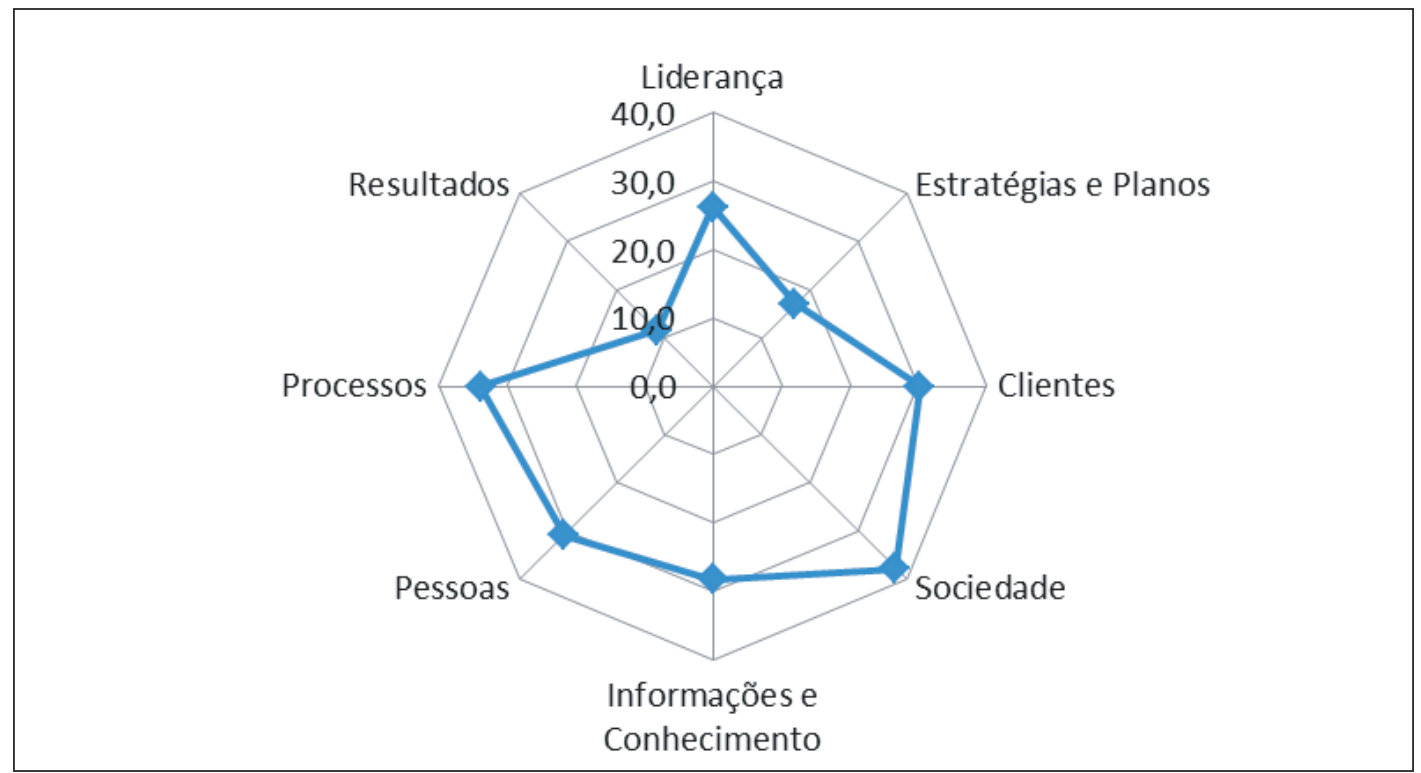

Fonte: Elaborado pelos autores.

No geral, considerando-se as empresas avaliadas, todos os indicadores estão baixos. Entretanto, pode-se perceber indicação especialmente pequena no critério "resultados", o que significa que os empresários conhecem pouco os principais indicadores gerenciais da empresa, já que são analisados satisfação e reclamações dos clientes, capacitações para colaboradores, acidentes com colaboradores, produtividade no trabalho e margem de lucro.
Por se tratar de resultado que foca o futuro da organização e porque os empresários têm pouco dessa perspectiva, o critério "estratégias e planos" também está abaixo da média dos demais critérios. Ele analisa definição da visão, alcance dos objetivos, estabelecimento de indicadores e metas e definição dos planos de ação. O Gráfico 2 demonstra as duas empresas que obtiveram melhor desempenho em relação aos critérios do MEG. 
Gráfico 2 - Representação por modelo aranha da empresa 1 e da empresa 2
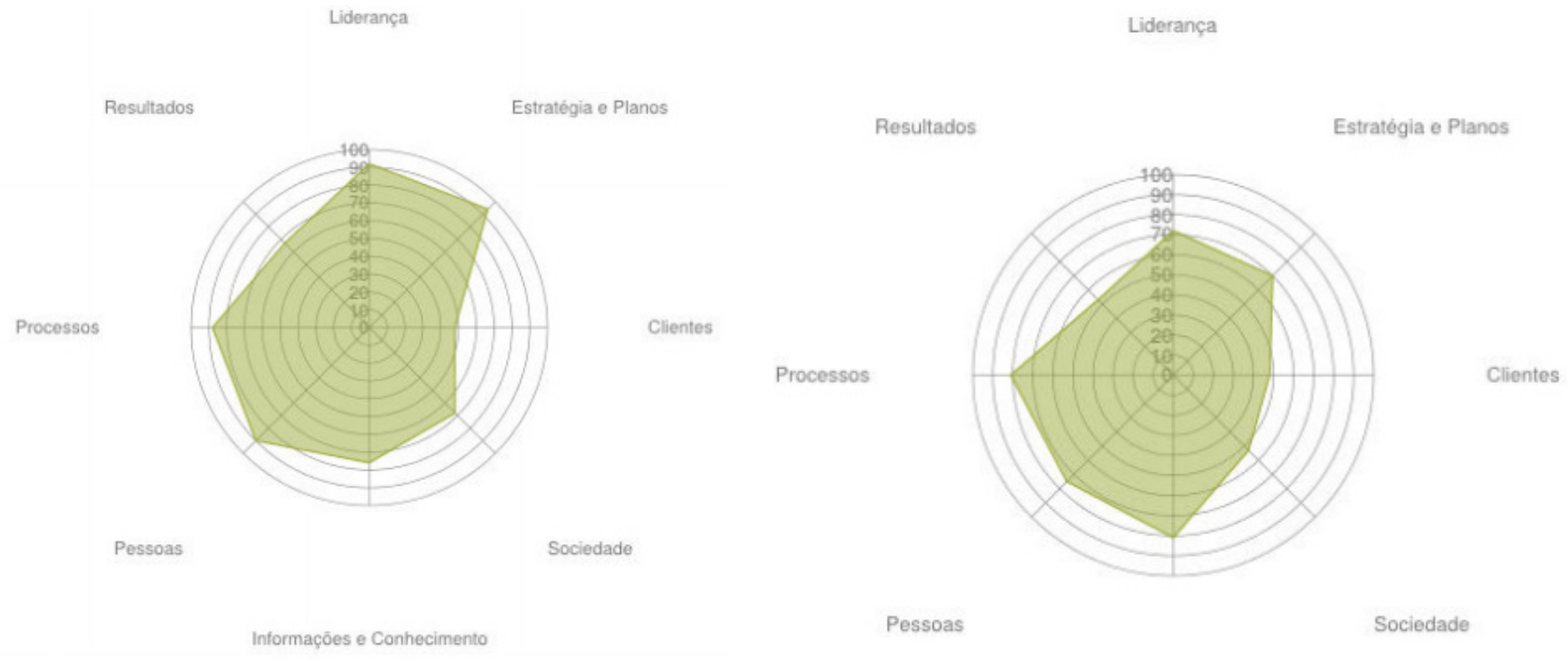

Fonte: Elaborado pelos autores.

As empresas 1 e 2 têm em comum o fato de seus proprietários buscarem conhecimento de gestão constantemente. Isso mostra a importância da busca de informação para a gestão da empresa e para a consequente maturidade empresarial. Das 25 empresas, as duas se destacaram e possuem informações precisas do negócio e evidências dos critérios elencados pela FNQ como relevantes para a inovação organizacional. Isso representa apenas $8 \%$ do total de empreendimentos e contrasta com os resultados obtidos na média das empresas avaliadas.

De modo geral, os resultados evidenciam que, pela média do grau de maturidade, os empreendimentos analisados encontram-se imaturos. Dessa maneira, os empresários necessitam avançar na gestão e melhorar seus indicadores. Recomenda-se que esses empreendedores avaliem melhor seus negócios, conheçam com mais precisão sua estrutura e adotem ferramentas de controle e evidenciação.

Por outro lado, esse resultado corrobora com pesquisas anteriores realizadas sobre o Polo de Confecções do Agreste Pernambucano, particularmente no município de Santa Cruz do Capibaribe (DIEESE, 2010; LIRA, 2006; SEBRAE/PE, 2013), que mostraram a alta taxa de informalidade dos empreendimentos, bem como uma melhoria da infraestrutura proporcionada pelo poder público.

Diante das expressões dos diversos autores (AMIN, 1999; LASTRES; CASSIOLATO, 2003a; LASTRES; CASSIOLATO, 2003b; PORTER, 1999; SCHMITZ, 1997) a respeito dos arranjos produtivos locais ou do processo de clustering, é possível afirmar que o processo de edificação e operacionalidade do Polo de Confecções do Agreste Pernambucano foi muito pouco aproveitado. O APL apresenta ainda hoje traços de modernização que está incompleta, mas pode se consolidar. Afinal, devem-se transformar as oportunidades em vantagens competitivas; as empresas devem se atualizar continuamente, buscar maturidade nos processos e eliminar a ineficiência operacional (CHRISSIS; KONRAD; SHRUM, 2011; FLEURY; FLEURY, 2000; PORTER, 1999).

Outro aspecto a ser pontuado que foi observado em campo com a aplicação do MEG é que os poderes públicos não se fizeram presentes nas políticas promotoras da competitividade do APL de maneira sistêmica, mas de maneira fragmentada ou pontual. 
Sendo assim, o reconhecimento da importância do desenvolvimento endógeno e da iniciativa local em processos de desenvolvimento territorial ou regional tem favorecido a consolidação dos arranjos produtivos locais ou do processo de clustering como política pública. Para que uma região se desenvolva econômica e socialmente, é imprescindível conhecer e investir em suas potencialidades, além de ter atores sociais com capacidade de promover as condições necessárias para concretização dos APL, conforme explicitaram outros autores (AMIN, 1999; LASTRES; CASSIOLATO, 2003a; LASTRES; CASSIOLATO, 2003b; SCHMITZ, 1997).

\section{CONSIDERAÇÕES FINAIS}

O objetivo desta pesquisa foi avaliar o grau de maturidade de empresas do setor têxtil e de confecções do Agreste pernambucano - precisamente no município de Santa Cruz do Capibaribe, através de diagnóstico gerencial da qualidade e da sustentabilidade dos empreendimentos, na ausência de experiências similares acerca dos APL, em Pernambuco. Com isso, foi possível evidenciar os aspectos positivos e os que estão dificultando o desenvolvimento do negócio e, sobretudo, perceber aspectos da gestão das empresas localizadas na região.

A análise do grau de maturidade de gestão, em linhas gerais, pode ser instrumento de emancipação e de capacitação para que os empresários determinem seu presente e para prepará-los para seu futuro. Isso, por si só, já reflete a sua importância no processo de desenvolvimento da cadeia produtiva. Todavia, o grau de maturidade está intrinsecamente relacionado com ganhos de competitividade que a empresa pode ter e que são cruciais nos dias de hoje.

A pesquisa evidenciou claramente que a média do grau de maturidade das empresas analisadas encontra-se no patamar de imaturidade. Além disso, o baixo grau de maturidade também representa baixa qualificação técnica e de gestão. Isso mostra que a carência de órgãos que visam a formação profissional em Santa Cruz do Capibaribe faz que toda a cadeia seja pouco inovadora e ineficiente.

Cabe salientar como limitações deste estudo o número reduzido de empresas participantes e a limitação a empresas formais, localizadas no município de Santa Cruz do Capibaribe. Desse modo, sugere-se a realização de estudos futuros que possam abranger maior número de empresas e de municípios que integram esse $A P L$, a fim de que os resultados possam ser comparados ou analisados em maior amplitude; sugere-se também a replicação deste estudo com as mesmas empresas no futuro, com intuito de verificar sua evolução.

Assim, o ambiente organizacional - seja ele de grande empresa, de microempresa ou até de instituição pública - precisa estar atento e compreender que é uma unidade integrante de um sistema aberto, consequentemente interagindo a todo tempo a partir de variáveis externas e internas. Para enfrentar essa dinâmica e suas variáveis, a organização precisa fazer sua vigilância sistemática.

É necessário analisar e compreender as possíveis tendências e descontinuidades, a fim de garantir a sua sobrevivência ao longo do tempo. Dessa maneira, quanto mais rápida for a adaptação das organizações ao seu ambiente externo, melhor para sua sobrevivência. As descontinuidades podem ser caracterizadas como mudanças bruscas no ambiente organizacional, embora as tendências e descontinuidades possam impactar, positiva ou negativamente, as atividades da organização.

Contudo, em razão das variáveis incontroláveis no macroambiente, emerge a importância do grau de maturidade da gestão ao subsidiar planejamento estratégico para desenvolvimento organizacional. Dessa maneira, aquelas organizações que atuam em clusters (sistemas produtivos, arranjos produtivos locais) têm mais chances de sobrevivência, pois tendem a exercer - por menor que seja - alguma influência no macroambiente. Para que isso ocorra, é necessário o respaldo institucional em prol do desenvolvimento local. 


\section{REFERÊNCIAS}

AMIN, A. An institutionalist perspective on regional economic development. International Journal of Urban and Regional Research, Oxford, v. 23, n. 2, p. 365-378, 1999.

BRASIL. Lei Complementar n 123, de 14 de dezembro de 2006. Institui o Estatuto Nacional da Microempresa e da Empresa de Pequeno Porte. Brasília, DF: Casa Civil, 2006. Disponível em: <http://www.planalto.gov.br/ccivil_03/ leis/LCP/Lcp123.htm\#art89>. Acesso em: 30 jan. 2017.

CASTELLS, M. A sociedade em rede. 3. ed. São Paulo: Paz e Terra, 1999.

CHRISSIS, M. B.; KONRAD, M.; SHRUM, S. CMMI for development: guidelines for process and product improvement. Boston: Addison-Wesley, 2011.

DIEESE - DEPARTAMENTO INTERSINDICAL DE ESTATÍSTICAS E ESTUDOS SOCIOECONÔMICOS. Relatório final: diagnóstico do setor têxtil e de confecções de Caruaru e região. Recife, 2010.

DUARTE, R. S.; FUSCO, W. Migração e emprego precário em dois contextos distintos: São Paulo e Toritama. Caderno CRH, Salvador, v. 21, n. 53, p. 337-347, 2008.

FLEURY, A.; FLEURY, M. T. L. Estratégias empresariais e formação de competência: um quebra-cabeça caleidoscópico da indústria brasileira. São Paulo: Atlas, 2000.

FNQ - FUNDAÇÃO NACIONAL DA QUALIDADE. Modelo de excelência da gestão. São Paulo, 2014a. Disponível em: <http://ftp2.fnq.org.br/2014/e-book_MEG.pdf>. Acesso em: 30 jan. 2017.

Prêmio de competitividade para micro e pequenas empresas: questionário de autoavaliação ciclo 2014. São Paulo, 2014b.

KOTLER, P.; ARMSTRONG, G. Introdução ao marketing. 4. ed. Rio de Janeiro: LTC; Person, 2000.

LASTRES, H. M. M.; CASSIOLATO, J. E. O foco em arranjos produtivos e inovativos locais de micro e pequenas empresas. In: LASTRES, H. M. M.; CASSIOLATO, J. E.; MACIEL, M. L. (Org.). Pequena empresa: cooperação e desenvolvimento local. Rio de Janeiro: Relume Dumará, 2003a.

LASTRES, H. M. M.; CASSIOLATO, J. E. (Org.). Glossário de arranjos e sistemas produtivos e inovativos locais. Rio de Janeiro: IE; UFRJ; Sebrae, 2003b. Disponível em: <http:// portalapl.ibict.br/export/sites/apl/galerias/arquivos_ noticias/glossario.pdf>. Acesso em: 30 jan. 2017.

LIRA, S. M. Os aglomerados de micro e pequenas indústrias de confecções do Agreste/PE: um espaço construído na luta pela sobrevivência. Revista de Geografia, Recife, v. 23, n. 1, p. 98-114, 2006.

MARSHALL, A. Princípios de economia.. São Paulo: Nova Cultura, 1996. (Coleção Os Economistas.)

MINAYO, M. C. S. (Org.) et al. Pesquisa social: teoria, método e criatividade. Petrópolis: Vozes, 2007.

MOREIRA, R. O Nordeste brasileiro: uma política regional de industrialização. Rio de Janeiro: Paz e Terra, 1979.

PORTER, M. E. Competição: estratégias competitivas essenciais. 7. ed. Rio de Janeiro: Campus, 1999.

SCHMITZ, H. Eficiência coletiva: caminho de crescimento para indústria de pequeno porte. Ensaios FEE, Porto Alegre, v. 18, n. 2, p. 164-200, 1997.

SCHUMPETER, J. A. Teoria do desenvolvimento econômico. Tradução Maria Sílvia Possas. São Paulo: Nova Cultural, 1997.

SEBRAE/PE - SERVIÇO BRASILEIRO DE APOIO ÀS MICRO E PEQUENAS EMPRESAS DO ESTADO DE PERNAMBUCO. Estudo econômico do arranjo produtivo local de confecções do Agreste pernambucano, 2012. Recife, 2013.

YIN, R. K. Estudo de caso: planejamento e métodos. 3. ed. Porto Alegre: Bookman, 2005. 